NBER WORKING PAPER SERIES

THE WELFARE EFFECT OF A CONSUMER SUBSIDY WITH PRICE CEILINGS: THE CASE OF CHINESE CELL PHONES

\author{
Ying Fan \\ Ge Zhang \\ Working Paper 28659 \\ http://www.nber.org/papers/w28659 \\ NATIONAL BUREAU OF ECONOMIC RESEARCH \\ 1050 Massachusetts Avenue \\ Cambridge, MA 02138 \\ April 2021
}

We thank the Cowles Foundation for Research in Economics, the Michigan Institute for Teaching and Research in Economics, and the NET Institute for their generous financial support. The views expressed herein are those of the authors and do not necessarily reflect the views of the National Bureau of Economic Research.

NBER working papers are circulated for discussion and comment purposes. They have not been peer-reviewed or been subject to the review by the NBER Board of Directors that accompanies official NBER publications.

(C) 2021 by Ying Fan and Ge Zhang. All rights reserved. Short sections of text, not to exceed two paragraphs, may be quoted without explicit permission provided that full credit, including () notice, is given to the source. 
The Welfare Effect of a Consumer Subsidy with Price Ceilings: The Case of Chinese Cell

Phones

Ying Fan and Ge Zhang

NBER Working Paper No. 28659

April 2021

JEL No. D4,H2,L1

\begin{abstract}
Subsidies to consumers may cause firms to charge higher prices, which offsets consumer benefits from subsidies. We study a subsidy program design that mitigates such price increases by making products' eligibility for a subsidy dependent on firms' commitment to price ceilings. To quantify the importance of such competition for eligibility, we develop a structural model and an estimation procedure that accommodate binding pricing constraints. We find that competition for eligibility mitigates the price increases arising from the subsidy and even leads to a reduction in prices for some products. It improves consumer and total surpluses while limiting government subsidy payments.
\end{abstract}

Ying Fan

Department of Economics

University of Michigan

611 Tappan Street

Ann Arbor, MI 48109

and NBER

yingfan@umich.edu

Ge Zhang

Yale University

ge.zhang@yale.edu 


\title{
The Welfare Effect of a Consumer Subsidy with Price Ceilings: The Case of Chinese Cell Phones*
}

\author{
Ying $\operatorname{Fan}^{\dagger}$ \\ Ge Zhang ${ }^{\ddagger}$ \\ University of Michigan, \\ Yale University \\ CEPR and NBER
}

March 30, 2021

\begin{abstract}
Subsidies to consumers may cause firms to charge higher prices, which offsets consumer benefits from subsidies. We study a subsidy program design that mitigates such price increases by making products' eligibility for a subsidy dependent on firms' commitment to price ceilings. To quantify the importance of such competition for eligibility, we develop a structural model and an estimation procedure that accommodate binding pricing constraints. We find that competition for eligibility mitigates the price increases arising from the subsidy and even leads to a reduction in prices for some products. It improves consumer and total surpluses while limiting government subsidy payments.
\end{abstract}

Keywords: subsidy, price ceiling, competition for eligibility, cell phone

JEL classification: L1, D4, H2

\section{Introduction}

Governments worldwide often use consumption subsidies or taxes — two sides of the same coin — to stimulate or discourage certain types of consumption. Examples include solar panel rebates and tobacco excise taxes. Policy makers also use consumption subsidies to help targeted disadvantaged consumers (e.g., food stamps and child-care subsidies) and constitute a major component of government expenditure. However, by shifting demand to the right, such subsidies may lead to higher prices, and the consumer surplus gain from the subsidy may be smaller than the government subsidy payments.

\footnotetext{
${ }^{*}$ We thank Steven Berry, Philip Haile, and seminar participants at Yale University for their constructive comments. We thank the Cowles Foundation for Research in Economics, the Michigan Institute for Teaching and Research in Economics, and the NET Institute for their generous financial support.

$\dagger^{\dagger}$ Department of Economics, University of Michigan, 250 Lorch Hall, Ann Arbor, MI 48109-1220; yingfan@umich.edu

‡Department of Economics, Yale University, New Haven, CT 06520-8268; ge.zhang@yale.edu
} 
In this paper, we study a subsidy program where firms compete to have their products eligible for a subsidy. Such competition motivates firms to lower prices and thus improves consumer surplus. Specifically, the program includes a bidding process where each participating firm proposes a list of products and a price ceiling for each proposed product. The program committee evaluates the proposals and determines the set of products eligible for the consumer subsidy. It is common knowledge that the price ceiling is a crucial determinant of a product's chance of becoming eligible. After the bidding, firms must set a subsidized product's retail price no higher than its respective price ceiling. To increase the probability of becoming eligible for the subsidy, a firm may have an incentive to commit to a low price ceiling. Thus, the ex-ante competition for subsidy eligibility may put downward pressure on prices, mitigating the price increase that would otherwise result from the consumer subsidy. Examples with similar policy designs include the infant formula rebate by the "Women, Infants, and Children" (WIC) program (Oliveira et al. 2010; Davis 2014) and the Low-Income Subsidy (LIS) for Medicare prescription drug coverage (Decarolis et al. 2020) in the US. $^{1}$

The subsidy program we study is called "Home Appliances Going to the Countryside" (henceforth, HAGC). Implemented in China from 2008 to 2012, it provided a rebate of up to $13 \%$ of the product price to consumers from the countryside if they purchased eligible home appliances and electronics. By the end of 2012, the HAGC program subsidized 298 million units of products that were sold for a total of 720.5 billion CNY. ${ }^{2}$ The total government spending on HAGC subsidies was around 90 billion CNY. In this paper, we focus on the subsidy for cell phones.

We quantify the welfare effect of the HAGC program on firms, subsidized consumers, and unsubsidized consumers. Unsubsidized consumers may also be affected by the program because firms set the same price for all consumers, and the program may lead to changes in prices. To highlight the role that firms' competition for subsidy eligibility plays in shaping the subsidy program's welfare implications, we further decompose the overall welfare effect into those due to the subsidy itself, the set of eligible products, and the price ceilings.

To this end, we set up a structural model of consumer demand and firm pricing. We specify a randomcoefficients discrete-choice demand model that allows consumers to differ in preferences and subsidy eligibility. We model the firms as strategically choosing prices to maximize profits subject to the constraint that they must price a subsidized product no higher than its price ceiling. We do not model or estimate the bidding process but instead take the eligible product set and the price ceilings as given. ${ }^{3}$ To address concerns about the selection in the bidding outcomes (i.e., the eligible product set and the price ceilings), we control for

\footnotetext{
${ }^{1}$ WIC assists low-income families and their children in purchasing healthy foods. In the infant formula rebate program by WIC, eligible households receive infant formula vouchers from state WIC agencies. The vouchers apply to a single infant formula brand in each state, as determined by a bidding process. Specifically, the manufacturer that offers the WIC state agency the lowest predicted net price, as determined by the manufacturer's wholesale price in the previous year minus the rebate, wins the exclusive contract. In the LIS program, only plans with a premium below the average premium in their market are eligible for low-income enrollees to obtain the full premium subsidy.

${ }^{2} \mathrm{CNY}$ is short for Chinese Yuan, the local currency in China. The exchange rate was 1 USD $=6.23 \mathrm{CNY}$ at the end of 2012 .

${ }^{3}$ We do not observe the list of participants or their submitted price ceilings and thus cannot estimate the bidding process. Correspondingly, in the counterfactual simulations, we focus on counterfactual designs where the set of eligible products do not change endogenously.
} 
firm, region, and time fixed effects in our model specification. We consider it reasonable to assume that the product/region/time-specific transitory shocks are unobservable to firms when they bid and to the evaluation committee when deciding on the winning bids.

The existence of (binding) pricing constraints is exactly why the competition for eligibility can mitigate price increases under subsidy and thus improve consumer surplus. However, such binding constraints imply that some firms' profit-maximization problem is a constrained one, which invalidates the usual supply estimation procedure based on the first-order optimality conditions (e.g., Berry et al. (1995), henceforth, BLP). Instead, we develop a procedure for marginal cost estimation (and counterfactual simulation) that accommodates binding pricing constraints. The basic idea is to first estimate marginal cost coefficients and the empirical distribution of marginal cost shocks using the sample of firms without eligible products, free of a sample selection bias given the aforementioned assumption on unobservables; then repeat a "drawand-verify" procedure to approximate the distribution of marginal costs for the firms with binding pricing constraint(s). We explain this method in detail in Section 5.2.

We assemble a dataset on the HAGC-eligible cell phones and their price ceilings from government documents, and link it to Chinese cell phone sales data from July 2007 to June 2013, covering the lifespan of the HAGC program. Using these data, we estimate demand and marginal cost parameters. Based on the estimated model, we conduct three counterfactual simulations to quantify the program's effects and to highlight the role of firms' competition for eligibility in mitigating price increases and improving consumer surplus.

We find that competition for eligibility mitigates price increases due to the subsidy program and even leads to a reduction in prices for some products. For example, the prices of the eligible products with binding price ceilings in the data are, on average, $10.05 \%$ lower than a scenario without a subsidy. Because prices are strategic complements, even though other products' prices increase due to the subsidy program, the increases are smaller than those under the same subsidy without price ceilings.

Overall, we find that the HAGC subsidy program increases the consumer surplus and producer surplus by, respectively, 3.07 and 2.77 billion $\mathrm{CNY}$, which are $68 \%$ and $61 \%$ of the total government subsidy payments. However, if there were no price ceilings resulting from competition for eligibility, these gains would be 2.76 billion and 2.97 billion $\mathrm{CNY}$ or $61 \%$ and $66 \%$ of the total government subsidy payments, respectively, indicating that the price ceilings improve consumer surplus in both level and share of the subsidy. If competition for eligibility were removed altogether (which determines both the eligibility set and the price ceilings), these percentages would become $95 \%$ and $37 \%$. However, the predicted total subsidy payments would be six times the actual payments and might not be financially feasible. These results indicate that firms' competition for subsidy eligibility in the program benefits consumers and increases total surplus while limiting the required government subsidy payments.

Our paper contributes to the literature on the welfare effects of consumption tax and subsidy policies. Many papers point out the role of market power in subsidy pass-through (or tax incidence). See, for example, 
Weyl and Fabinger (2013) for a theoretical discussion, Cabral et al. (2018) on Medicare Advantage subsidies, Polyakova and Ryan (2019) on Affordable Care Act subsidies, Pless and van Benthem (2019) on solar panel subsidies in California, and Sallee (2011) on hybrid car tax credits. However, there is little work on the role of price ceilings or other price controls in subsidy or tax policies. Our paper adds to the literature by highlighting the role of particular policies designed to tackle what hinders consumer gains from the subsidy the price increase arising from the subsidy. Our paper suggests that such policy designs can benefit consumers while limiting government expenditure.

By studying a subsidy program targeting disadvantaged consumers in a developing country, our paper contributes to the literature on the evaluation of subsidy programs in less developed economies. Among the studies on the HAGC subsidy program, Chen et al. (2015) assess the impact of household technology on health outcomes, while Tewari and Wang (2020) estimate its impact on female labor force participation. Like these papers, we investigate a subsidy program that aims to help disadvantaged consumers. Unlike most of these papers, we quantify the direct impacts of the subsidy program on consumption and welfare, rather than the indirect impacts on socioeconomic outcomes.

Our paper is also related to the empirical research on cell phone or smartphone markets. For example, Wang (2020) studies how entry affects product portfolio choices in the Chinese smartphone market, Fan and Yang (2020) study the welfare effects of endogenous product choices and competition in the US smartphone market, and Zhu et al. (2015) and Sinkinson (2020) study exclusive contracting for early iPhones. We complement these papers by studying a consumer subsidy in this industry.

We complete the literature review by comparing our supply model and some models in the trade and environmental economics literature. In these models, firms also face certain constraints, and Lagrange multipliers are included in optimality conditions as (often nuisance) parameters. For example, in Goldberg (1995), some firms face export quotas, and each constrained firm is subject to one constraint when choosing prices for all its products. In our case, however, a firm faces one (different) price ceiling for each of its subsidyeligible products, leaving no variation for us to identify the (hundreds of) Lagrange multiplier parameters. Instead, we develop an estimation procedure as explained in Section 5.2

The remainder of this paper proceeds as follows. Section 2 provides background information on the HAGC subsidy program. Section 3 describes our data. Section 4 sets up our structural model, and Section 5 discusses our estimation procedure and reports the estimates. In Section 6 , we conduct counterfactual simulations for welfare analysis. We conclude in Section 7

\section{$2 \quad$ Background}

\subsection{HAGC Subsidy Program Overview}

Home Appliances Going to the Countryside (HAGC) was a subsidy program effective between 2008 and 2012 in China. This program provided subsidies to targeted consumers if they purchased eligible home 
appliances and electronics. The main goals were to improve the quality of life for the relatively low-income rural population and to stimulate domestic consumption when China's exports declined severely due to the 2008 financial crisis. The HAGC program was first launched as a pilot program in three provinces in December 2007, expanded to twelve more provinces in November 2008, and eventually to all the other provinces in mainland China in January 2009. It was first terminated in the three pilot provinces in December 2011, then in the next twelve provinces in November 2011, and finally in all the remaining provinces in January 2013. ${ }^{4}$ The HAGC subsidy program was a sizable program with total government spending of 90 billion CNY on 298 million units of subsidized products sold for a total of 720.5 billion CNY by the end of 2012.

Four categories of products were subsidized nationwide, including color TVs, refrigerators, and cell phones since the beginning of the pilot program, and washing machines since 2009. Each province was allowed to choose several additional product categories such as air conditioners, water heaters, computers, microwave ovens, and electromagnetic cookers.

In this paper, we focus on the cell phone market for two reasons. First, the cell phone category was one of the four categories available in all provinces, for which we have richer data than the regional product categories. As will be explained later, we exploit cross-province and cross-time variations in the set of subsidy-eligible products for estimation. Second, there were concurrent additional subsidy programs for the other three national categories, but not for cell phones. For example, for TVs, refrigerators, and washing machines, there was a trade-in promotion in 2009-2011 and a subsidy program for energy-saving products in 2012-2013.

The subsidy was in the form of a rebate. If a consumer was eligible for the subsidy and purchased a qualified product, she paid the same retail price as ineligible consumers but would receive a rebate of $13 \%$ of the retail price up to a maximum rebate of $130 \mathrm{CNY}$ for a cell phone. ${ }^{5}$ Consumers were very likely to be aware of products' eligibility status and effective prices because the HAGC program was one of the most important subsidy policies in China around 2010, the public media widely and repeatedly reported on the HAGC program, and there was an HAGC label on the package of each eligible product.

\subsection{Product Eligibility and Incentives to Curb Prices}

A critical component of the HAGC program was the firms' competition for subsidy eligibility. The set of products eligible for the subsidy was determined by a bidding process. There were six rounds of bidding from 2008 to 2012. In each round, each participating firm proposed a list of products and a corresponding price ceiling for each product, together with a list of provinces. ${ }^{6}$ If a product was eventually chosen to be eligible for the HAGC subsidy in a province, the price ceiling became a constraint to the product's firm when

\footnotetext{
${ }^{4}$ The different ending times ensured that residents in each province were eligible for the subsidy for the same length of time.

${ }^{5}$ Each consumer was allowed for up to two rebates per year on cell phone purchases, which was unlikely to be a binding restriction for most consumers.

${ }^{6}$ The list of provinces must be the same for all the listed products, and the price ceiling for a listed product must be the same for all the listed provinces.
} 
choosing its retail price in the province.

A committee from China's Ministry of Finance and Ministry of Commerce evaluated these proposals based on product characteristics, firm characteristics (e.g., previous sales, customer service in each province), and, most importantly, the price ceiling. Although the evaluation criteria might be opaque, it was common knowledge that submitting a lower price ceiling, ceteris paribus, would increase the chance of a product being chosen for the program. Such competition for subsidy eligibility curbed firms' incentives to raise prices under the subsidy.

Figure 1 presents a hypothetical example of a firm's original proposal and winning proposal. Multiple products from multiple firms could be eligible for the subsidy simultaneously. The evaluation committee might decline some of the products and some of the provinces on a proposal while accepting the other products and provinces as winners, but they would never impose a price ceiling different from that on the proposal. While we do not observe the original proposals that firms submitted (i.e., the left panel of Figure 1), the winning proposals (i.e., the right panel of Figure 1) were publicly announced and observable to researchers.

Unobserved Original Proposal

\begin{tabular}{|c|c|c|c|}
\hline Firm & Product & Ceiling & Province \\
\hline \multirow{3}{*}{ BIRD } & Bird S368 & 299 & Anhui, \\
\cline { 2 - 3 } & Bird T800 & 899 & $\begin{array}{l}\text { Gansu, } \\
\text { Hunan }\end{array}$ \\
\cline { 2 - 3 } & Bird D719 & 599 & Hun \\
\hline
\end{tabular}

Observed Winning Proposal

\begin{tabular}{|c|c|c|c|}
\hline Firm & Product & Ceiling & Province \\
\hline \multirow{3}{*}{ BIRD } & Bird S368 & 299 & \multirow{3}{*}{$\begin{array}{c}\text { Anhui, } \\
\text { Gansu }\end{array}$} \\
\cline { 2 - 3 } & Bird T800 & 899 & \\
\cline { 2 - 3 } & & & \\
\hline
\end{tabular}

Figure 1: A Hypothetical Example of a Proposal

There are some details about the pricing restrictions that are worth noting. First, a product was not subject to a price ceiling in a province if it was not a subsidy-qualifying product in the province. Second, although a subsidized product was subject to the same price ceiling across eligible provinces and months, firms could and did set different retail prices across provinces and months. Third, retail prices were the same for all consumers in the same province and month, no matter whether the consumer was eligible for the subsidy or not (Section 2.3). Fourth, proposed price ceilings in the cell phone category must be below 1,000 CNY in 2008-2009 and below 2,000 CNY in 2010-2012.

\subsection{Consumer Eligibility and Hukou}

Roughly 0.9 billion Chinese citizens, or $70 \%$ of the national population, were eligible for the HAGC subsidy. A consumer was eligible if and only if she had a so-called "Agricultural Hukou". Hukou is a household registration system used in mainland China where the household register is issued per family. Historically, Hukou officially identified a person as a permanent resident of an area: agricultural Hukou meant one's permanent residence was in a rural area, and non-agricultural Hukou meant permanent residency in an urban area. However, due to rapid urbanization and massive migration within China, Hokou was no longer 
a good description of whether a person mostly lived and worked in a rural or urban area by the time of the HAGC program (as will be shown in the next section).

Nonetheless, the Chinese government often assigns social benefits based on agricultural or non-agricultural Hukou status (Wang 2014). One reason is that the government has the official record of Hukou information for every citizen in mainland China. When the government implements a social benefit program, it is much less time- and labor-consuming to verify Hukou status than income level and residence location. Another reason is that the Hukou registration type (agriculture/non-agriculture) was given to a person at her birth based on her parents' Hukou types and thus is prohibitively difficult and costly to change in the short run. Assigning benefits based on Hukou helps to prevent people from abusing benefits by taking actions to become eligible for social programs. Due to these two reasons, the HAGC subsidy program used agriculture Hukou as the eligibility criterion for simplicity despite the aim to help low-income residents in the countryside, and it is reasonable for us to assume that consumers did not change Hukou types in response to the HAGC program.

Given the difference between Hukou and residence, we distinguish them in our analysis. While the former distinction (agriculture vs. non-agriculture) determines the subsidy eligibility, the latter (rural vs. urban residents, or population in a rural vs. urban area) is assumed to be relevant for consumer preferences in the demand model. The significant variation in residence and Hukou proportions across markets helps identify our demand model.

\section{Data}

Our cell phone sales data come from GfK, a leading market research company for consumer products. The data set includes the universe of cell phones sold in mainland China between July 2007 and June 2013, which spans six months before the HAGC program to six months after it. We observe the total number of units sold and the average price for each cell phone product in every month in the sample and every province in mainland China.

The price in the sales data is for a cell phone handset, excluding any promotion or service charge set by mobile carriers. Note that the majority of cell phone handsets in China were sold separately from a wireless network service contract during the time of the data, according to industry analysis reports. Thus, we can make the reasonable simplifying assumption that the cell phone firms choose the final retail prices to the end consumers in our model.

Key characteristics of each product are also available in the data set. Specifically, we observe whether a product is a smartphone or a feature phone, whether it includes a camera, whether it includes a touch screen, whether it supports the 3G network, whether it supports dual SIM, whether it has a "flip" or "slider" design, ${ }^{7}$

\footnotetext{
7 "Flip" means that this cell phone has a flip, and the flip may include functions like a microphone, keyboard, or camera. "Slider" means that this cell phone has an orientation where the keypad is not visible, and it needs to be pulled or pushed out for the keypad to be revealed.
} 
storage in gigabytes, camera resolution in megapixels, and handset size in inches. On the rare occasions of missing characteristics data, we hand-collected the information from The List of Telecommunications Equipment Approved for Network Access Licenses (Including Trial Approvals) (in Chinese) by China's Ministry of Industry and Information Technology (henceforth, the MIIT list) and GSMArena.com.

Data on the winning proposals come from the China National Electronics Import and Export Corporation, the HAGC subsidy program's bidding agency. We observe the eligible products, their price ceilings, the eligible provinces, and the effective dates for each bidding round. We then link the HAGC subsidy data to the Chinese cell phone sales data by matching the product model name (and the eligible markets).

Data on demographics come from the National Bureau of Statistics of China (NBS). The NBS provides data on the numbers of rural and urban residents each year and province, but not by Hukou type. One exception is that in the 2010 Population Census, the NBS provides the provincial-level data on four types of residents: rural residents with agricultural Hukou, urban residents with agricultural Hukou, rural residents with non-agricultural Hukou, and urban residents with non-agricultural Hukou. Using these data from the 2010 Census, we compute the conditional proportions $\operatorname{Pr}$ (agriculture Hukou | urban residents) and $\operatorname{Pr}$ (agriculture Hukou|rural residents). We combine these province-level conditional proportions with province/year-level data on the numbers of rural and urban residents to obtain our measure of the populations of all four types in each province and each year.

We consider a province/quarter combination to be a market. A vast majority of consumers in China bought cell phones from a local retail market during our sample period: online sales account for $8.75 \%$ of the total sales units in our data. We drop online sales because our data source reports online sales only at the national level without providing a breakdown at the province level. In the end, our sample consists of 98,446 observations (product/province/quarters) from 728 markets (province/quarters). There are 3,457 distinct products and 205 distinct firms, among which 390 products and 20 firms are ever eligible for the HAGC subsidy. See Appendix A for details on our sample construction.

Table 1 presents the summary statistics of sales units, price, and key characteristics at the observation level. The first four columns report summary statistics for the full sample, the fifth for subsidized observations, and the last for observations with binding pricing constraints (i.e., the retail price equals the price ceiling). From the table, we can see that the average of the subsidized products is lower than that of the full sample for the retail price and across all product characteristics, indicating that the HAGC program focused on low-end products. The existence of the 453 observations with binding pricing constraints shows the effectiveness of firms' competition for subsidy eligibility in mitigating price increases under subsidy and improving consumer surplus. Since prices are strategic complements, they are likely to also put downward pressure on other non-binding or unsubsidized products. We show and quantify these effects explicitly later.

Figure 2 plots the histograms of the price ceilings and the ratios of retail prices to price ceilings for the observations of the subsidized products. The upper panel shows the distribution of price ceilings in CNY. The median, indicated by the vertical line, is $658 \mathrm{CNY}$. The distribution is skewed to the left, consistent with 
the HAGC program's focus on low-end products. There is bunching at or just below 1,000 CNY because firms could not propose a price ceiling above 1,000 CNY in 2008 and 2009. The lower panel shows the distribution of the ratios of retail prices to price ceilings, with a median of $82 \%$. The observations on the right end of the panel are those with binding pricing constraints or with prices close to their price ceilings.

Table 1: Summary Statistics of Cell Phone Sales and Characteristics

\begin{tabular}{|c|c|c|c|c|c|c|}
\hline \multirow[b]{2}{*}{ Variable } & \multicolumn{4}{|c|}{ Overall } & \multirow{2}{*}{$\begin{array}{c}\text { Subsidized } \\
\text { Mean }\end{array}$} & \multirow{2}{*}{$\frac{\text { Binding }}{\text { Mean }}$} \\
\hline & Mean & Std & Min & Max & & \\
\hline Number of units sold & 6,536 & 13,935 & 500 & 893,457 & 8,299 & 5,454 \\
\hline Retail price $(1,000 \mathrm{CNY})$ & 1.00 & 0.63 & 0.11 & 3.00 & 0.59 & 0.61 \\
\hline Smartphone (v.s. feature phone) & 0.25 & & & & 0.08 & 0.01 \\
\hline Include camera & 0.77 & & & & 0.60 & 0.55 \\
\hline Include touch screen & 0.32 & & & & 0.20 & 0.21 \\
\hline Support 3G network & 0.30 & & & & 0.17 & 0.18 \\
\hline Dual SIM card & 0.13 & & & & 0.07 & 0.25 \\
\hline Design: flip & 0.10 & & & & 0.07 & 0.10 \\
\hline Design: slider & 0.17 & & & & 0.15 & 0.10 \\
\hline Storage memory (GB) & 1.08 & 1.10 & 0.01 & 16.00 & 0.94 & 0.99 \\
\hline Camera resolution (MP) & 2.00 & 1.52 & 0.10 & 12.00 & 1.24 & 1.12 \\
\hline Handset size (inch) & 4.67 & 0.37 & 2.88 & 8.74 & 4.56 & 4.61 \\
\hline Number of Observations & \multicolumn{4}{|c|}{98,446} & 11,309 & 453 \\
\hline
\end{tabular}
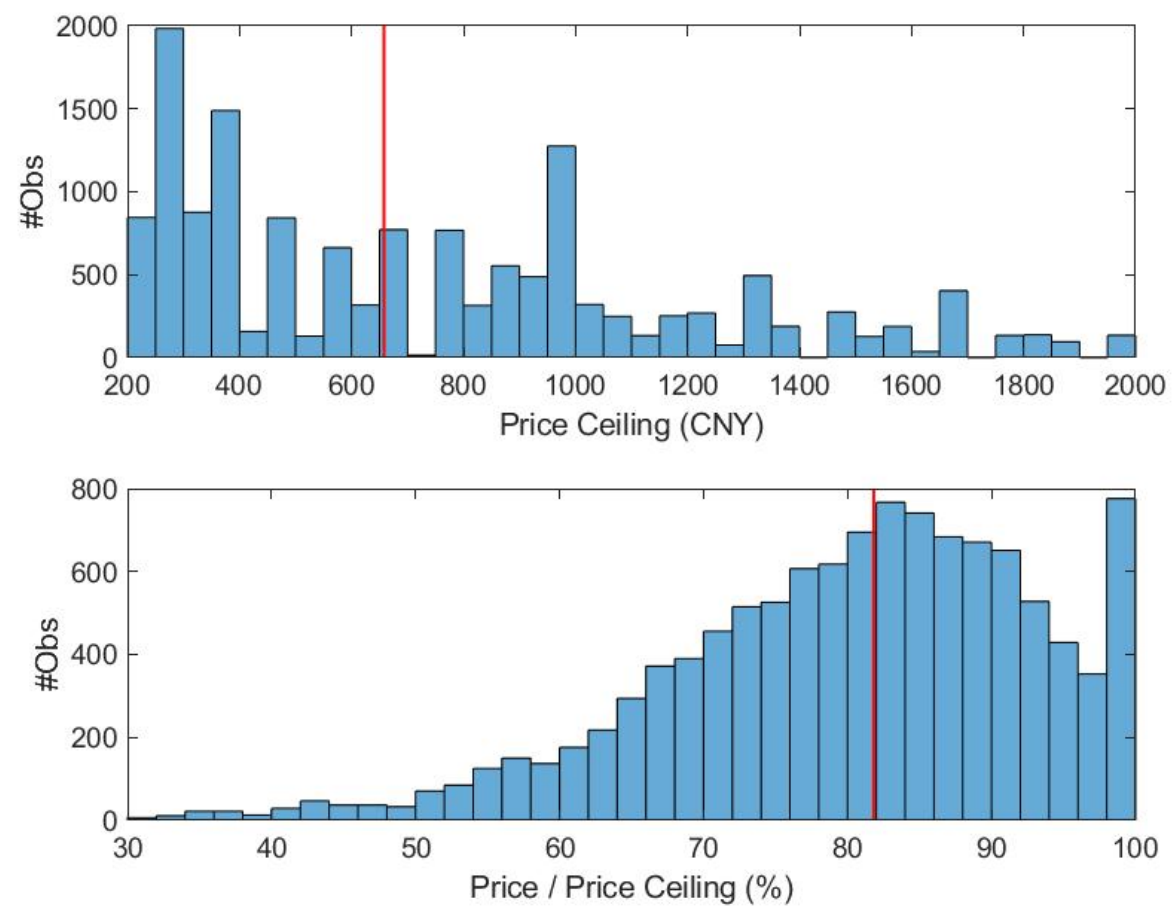

Figure 2: Histograms of Price Ceilings

Figure 3 shows the distribution of population proportions across markets. Each of the four panels 
corresponds to a combination of a residence type (rural or urban) and a Hukou type (agriculture or nonagriculture). For each market, the four percentages in the four panels add up to $100 \% .{ }^{8}$ From the upper right panel, we can see many markets with a sizable proportion of consumers living and working in an urban area while being registered as agricultural Hukou. Therefore, it is important to distinguish these two different categorizations of consumers. From the figure, we can also see significant variation in residence and Hukou proportions across markets, which helps our demand estimation as subsidy eligibility depends on Hukou while consumer tastes in our model depend on residence location.
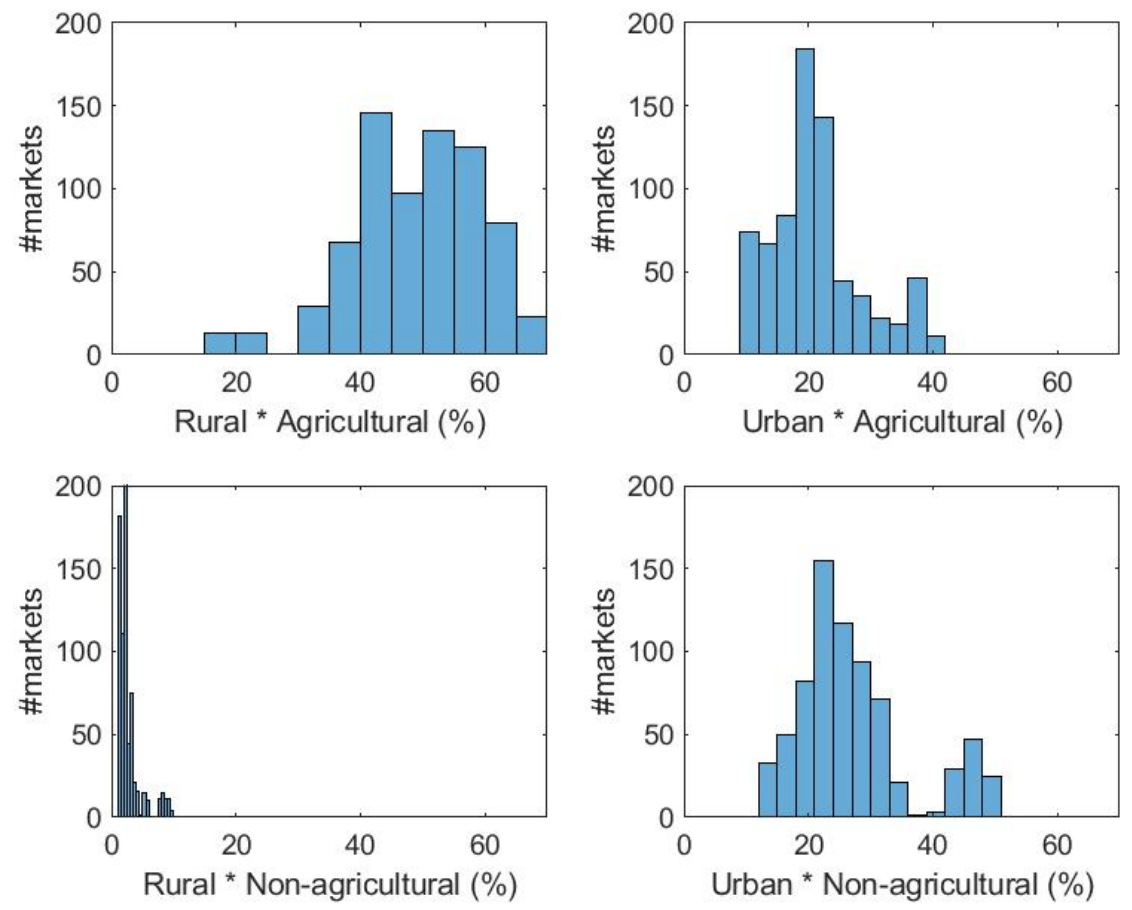

Figure 3: Population Proportions by Hukou and Residence Location

\section{Model}

\subsection{Demand Model}

We specify a random-coefficients discrete-choice demand model. There are four types of consumers determined by their Hukou type ( $h=A$ for agriculture Hukou, and $h=N A$ for non-agriculture Hukou) and their residence location ( $l=R$ for being in a rural area, and $l=U$ for being in an urban area). Consumers with different Hukou types face different effective prices for products eligible for the HAGC subsidy. We allow consumers with different residence locations to have different preferences on price and cell

\footnotetext{
${ }^{8}$ For example, in the Heilongjiang province in $2010,40 \%$ of the total population were people with agricultural Hukou in rural locations, $5 \%$ for agricultural Hukou in urban, $10 \%$ for non-agricultural Hukou in rural, and the remaining $45 \%$ for non-agricultural Hukou in urban.
} 
phone characteristics. Preference is more likely to differ across residence locations than Hukou types because factors that affect cell phone demand, such as how consumers use cell phones in daily life, are more related to where they currently live and work than their household registration type in the government's system.

Specifically, the utility that consumer $i$ with Hukou $h$ and residence $l$ in province $m$ and quarter $t$ gets from purchasing product $j$ (produced by firm $f(j)$ ) is

$$
u_{i j m t}^{h, l}=\rho^{l}+\beta X_{j}+\tilde{\alpha}_{i m t}^{l}\left(p_{j m t}-b_{j m t}^{h}\left(p_{j m t}\right)\right)+\text { Firm }_{f(j)}^{d}+\text { Province }_{m}^{d}+\text { Time }_{t}^{d}+\xi_{j m t}+\varepsilon_{i j m t},
$$

where $X_{j}$ is a vector of observable product characteristics, $p_{j m t}$ is the retail price, and $b_{j m t}^{h}\left(p_{j m t}\right)$ is the subsidy amount, which depends on whether $j$ is eligible for the subsidy in market $m t$, whether the consumer is eligible for the subsidy, and the retail price of the product. Specifically, let $\mathcal{J}_{m t}$ and $\mathcal{J}_{m t}^{e}$ represent, respectively, the set of all products and the set of products eligible for the subsidy in market $m t$. For consumers with non-agricultural Hukou $(h=N A)$ or for products that are not eligible for the subsidy $\left(j \in \mathcal{J}_{m t} \backslash \mathcal{J}_{m t}^{e}\right), b_{j m t}^{h}=0$. For consumers with agricultural Hukou $(h=A)$ and eligible products $\left(j \in \mathcal{J}_{m t}^{e}\right)$, the subsidy is $13 \%$ of the retail price up to a maximum of $130 \mathrm{CNY}$. In sum, $b_{j m t}^{h}\left(p_{j m t}\right)=\mathbb{1}\{h=A\}$. $\mathbb{1}\left\{j \in \mathcal{J}_{m t}^{e}\right\} \cdot \min \left\{p_{j m t}, 1000\right\} \cdot 13 \%$.

The random coefficient $\tilde{\alpha}_{i m t}^{l}$ captures consumers' heterogeneous price sensitivity and is assumed to follow a normal distribution depending on consumer $i$ 's residence location, i.e., $\tilde{\alpha}_{i m t}^{l}=\alpha^{l}+\sigma_{\alpha} \nu_{i}$, where $\nu_{i} \stackrel{i i d}{\sim} N(0,1)$. We also allow consumers' general taste for cell phones, $\rho^{l}$, to differ by consumers' residence location.

We allow for demand-side fixed effects Firm $_{f(j)}^{d}$, Province ${ }_{m}^{d}$, and Time $_{t}^{d}$ in the utility function (1) to capture systematic differences across firms, provinces, and quarters. We also include the term $\xi_{j m t}$ to capture the unobservable demand shock at the product/province/quarter level.

Finally, the term $\varepsilon_{i j m t}$ captures consumer $i$ 's idiosyncratic taste and is assumed to be i.i.d. across individual consumers and markets. We assume that $\varepsilon_{i j m t}$ follows a generalized extreme value distribution allowing correlations across products. Specifically, we group products into three nests (smartphones, feature phones, and the outside option) and allow for correlations in $\varepsilon_{i j m t}$ among products of the same nest. Let $\lambda$ be the nested Logit correlation coefficient. We normalize the utility of the outside option to be $u_{i 0 \mathrm{mt}}^{h, l}=\varepsilon_{i 0 \mathrm{mt}}$.

Define the mean utility of product $j$ for consumers of type $(h, l)$ in market $m t$ as

$$
\delta_{j m t}^{h, l}=\rho^{l}+\beta X_{j}+\alpha^{l}\left(p_{j m t}-b_{j m t}^{h}\left(p_{j m t}\right)\right)+\text { Firm }_{f(j)}^{d}+\text { Province }_{m}^{d}+\text { Time }_{t}^{d}+\xi_{j m t},
$$

and let

$$
\mu_{i j m t}^{h}=\sigma_{\alpha} \nu_{i}\left(p_{j m t}-b_{j m t}^{h}\left(p_{j m t}\right)\right) .
$$

Then, the utility function (1) can be written as $u_{i j m t}^{h, l}=\delta_{j m t}^{h, l}+\mu_{i j m t}^{h}+\varepsilon_{i j m t}$.

Let $\mathcal{J}_{\text {gmt }}$ be the set of products in market $m t$ that belong to nest $g, G\left(\nu_{i}\right)$ denote the distribution of $\nu_{i}$, and $\left(\boldsymbol{\delta}_{m t}^{h, l}, \boldsymbol{p}_{m t}\right)$ be the collection of $\left(\delta_{j m t}^{h, l}, p_{j m t}\right)$ for all $j \in \mathcal{J}_{m t}$. The probability that a consumer of type 
$(h, l)$ chooses product $j$ of nest $g$ in market $m t$ is

$$
s_{j m t}^{h, l}\left(\boldsymbol{\delta}_{m t}^{h, l}, \boldsymbol{p}_{m t}\right)=\int \frac{\exp \left\{\left(\delta_{j m t}^{h, l}+\mu_{i j m t}^{h}\right) /(1-\lambda)\right\}}{D_{g}^{\lambda}\left(\sum_{g^{\prime}} D_{g^{\prime}}^{(1-\lambda)}\right)} d G\left(\nu_{i}\right),
$$

where

$$
D_{g}=\sum_{j^{\prime} \in \mathcal{J}_{g m t}} \exp \left\{\left(\delta_{j^{\prime} m t}^{h, l}+\mu_{i j^{\prime} m t}^{h}\right) /(1-\lambda)\right\}
$$

We aggregate the consumer type-specific market share function to obtain the product/province/time level market share as

$$
\sum_{(h, l)} \tau_{m t}^{h, l} s_{j m t}^{h, l}\left(\boldsymbol{\delta}_{m t}^{h, l}, \boldsymbol{p}_{m t}\right)
$$

where $\tau_{m t}^{h, l}$ is the population proportion of consumers of type $h, l$ in market $m t$.

\subsection{Supply Model}

We describe the supply side by Bertrand competition. Firms with no eligible products solve a standard profit maximization problem, while firms with eligible products choose prices subject to the price ceilings of their eligible products.

Denote the product set of firm $f$ by $\mathcal{J}_{f m t}$ and the set of its subsidized products by $\mathcal{J}_{\text {fmt }}^{e}$, and define $\boldsymbol{p}_{f m t}=\left(p_{j m t}\right)_{j \in \mathcal{J}_{f m t}}$ to be the retail prices for firm $f$ 's products. We now rewrite the market share function in (5) as $s_{j m t}\left(\boldsymbol{p}_{f m t}, \boldsymbol{p}_{-f m t}\right)$ where its dependence on $\boldsymbol{\delta}_{m t}^{h, l}$ (and other factors) is absorbed in the subscription $j m t$. Given the retail prices of the competitors in the market $\left(\boldsymbol{p}_{-f m t}\right)$ and marginal cost $m c_{j m t}$, firm $f$ chooses its prices $\boldsymbol{p}_{f m t}$ to maximize its profit:

$$
\begin{aligned}
& \max _{\boldsymbol{p}_{f m t}} \sum_{j^{\prime} \in \mathcal{J}_{f m t}}\left(p_{j^{\prime} m t}-m c_{j^{\prime} m t}\right) s_{j^{\prime} m t}\left(\boldsymbol{p}_{f m t}, \boldsymbol{p}_{-f m t}\right), \\
& \text { s.t. } p_{j^{\prime} m t} \leq \bar{p}_{j^{\prime} t} \text { for } j^{\prime} \in \mathcal{J}_{f m t}^{e} .
\end{aligned}
$$

For a firm $f$ without any eligible products, i.e., $\mathcal{J}_{f m t}^{e}=\emptyset$, the problem in (6) becomes an unconstrained optimization problem.

The optimality condition gives that

$$
\begin{array}{ll}
\sum_{j^{\prime} \in \mathcal{J}_{f m t}}\left(p_{j^{\prime} m t}-m c_{j^{\prime} m t}\right) \frac{\partial s_{j^{\prime} m t}}{\partial p_{j m t}}+s_{j m t}=0 & \text { for } j \notin \mathcal{J}_{f m t}^{e} \text { or } p_{j m t}<\bar{p}_{j t}, \\
\sum_{j^{\prime} \in \mathcal{J}_{f m t}}\left(p_{j^{\prime} m t}-m c_{j^{\prime} m t}\right) \frac{\partial s_{j^{\prime} m t}}{\partial p_{j m t}}+s_{j m t} \geq 0 & \text { for } j \in \mathcal{J}_{f m t}^{e} \text { and } p_{j m t}=\bar{p}_{j t} .
\end{array}
$$

In other words, for non-eligible products or eligible products with non-binding price ceilings, the equation (7) holds; for eligible products with binding price ceilings, however, the inequality (8) holds. 
We assume the marginal cost is

$$
m c_{j m t}=\gamma X_{j}+\text { Firm }_{f(j)}^{s}+\text { Province }_{m}^{s}+\text { Time }_{t}^{s}+\omega_{j m t},
$$

where Firm $_{f(j)}^{s}$, Province ${ }_{m}^{s}$, Time $_{t}^{s}$ are supply-side fixed effects at various levels and $\omega_{j m t}$ is the unobservable marginal cost shock.

We complete this section with a discussion about the bidding process. Due to the lack of data on the proposals that firms submitted but did not win, we do not observe the set of participants and their proposals (products, price ceilings, and provinces). Therefore, we do not explicitly estimate the bidding process. To rule out selection (on unobservable shocks) in subsidy eligibility, as determined by the bidding process, we assume that marginal cost shocks are realized after the bidding process, i.e., the shocks are unobserved to firms when submitting their bids and to the evaluation committee when choosing winning bids. This timing assumption is reasonable because we include firm-, province- and time-specific fixed effects in the marginal cost specification, and thus the shocks are only product/region/time-specific transitory ones. Our estimation in Section 5 relies on this timing assumption.

\section{Estimation}

\subsection{Demand Estimation}

The demand estimation is a slight extension to that in BLP. Our market share data are at the product/province/quarter level. While there are four types of consumers who differ in preferences and subsidy eligibility and the overall market share is a weighted average of the type-specific market shares, we can extend the inversion results in BLP to solve for the unobservable demand shocks $\xi_{j m t}$ as a function of parameters and data. Specifically, note that according to the definition of the mean utility in (2), the four mean utility values have the following relation:

$$
\begin{aligned}
& \delta_{j m t}^{N A, R}=\delta_{j m t}^{A, R}+\alpha^{R} b_{j m t}^{A} ; \\
& \delta_{j m t}^{A, U}=\delta_{j m t}^{A, R}+\left(\rho^{U}-\rho^{R}\right)+\left(\alpha^{U}-\alpha^{R}\right)\left(p_{j m t}-b_{j m t}^{A}\right) ; \\
& \delta_{j m t}^{N A, U}=\delta_{j m t}^{A, R}+\left(\rho^{U}-\rho^{R}\right)+\left(\alpha^{U}-\alpha^{R}\right) p_{j m t}+\alpha^{R} b_{j m t}^{A} .
\end{aligned}
$$

Using (10), we can define the market share function in (5) as

$$
s_{j m t}\left(\boldsymbol{\delta}_{m t}^{A, R}, \boldsymbol{p}_{m t}, \boldsymbol{\tau}_{m t}\right)=\sum_{(h, l)} \tau_{m t}^{h, l} s_{j m t}^{h, l}\left(\boldsymbol{\delta}_{m t}^{h, l}, \boldsymbol{p}_{m t}\right)
$$

where $\boldsymbol{\tau}_{m t}=\left(\tau_{m t}^{A, R}, \tau_{m t}^{N A, R}, \tau_{m t}^{A, U}, \tau_{m t}^{N A, U}\right)$. The market share function in (11) is a function of $\delta_{j m t}^{A, R}$ but not the mean utilities of the other three consumer types. Equaling (11) to the market share in data $s_{j m t}$ (for 
all $j \in \mathcal{J}_{m t}$ ), we can solve for the mean utility $\delta_{j m t}^{A, R}\left(\boldsymbol{s}_{m t}, \boldsymbol{p}_{m t}, \boldsymbol{\tau}_{m t}, \rho^{U}-\rho^{R}, \alpha^{R}, \alpha^{U}\right)$, where $\boldsymbol{s}_{m t}$ denotes the collection of $s_{j m t}$ for all $j \in \mathcal{J}_{m t}$. Then we have the estimation equation as:

$$
\begin{aligned}
& \delta_{j m t}^{A, R}\left(\boldsymbol{s}_{m t}, \boldsymbol{p}_{m t}, \boldsymbol{\tau}_{m t}, \rho^{U}-\rho^{R}, \alpha^{R}, \alpha^{U}\right) \\
= & \rho^{R}+\beta X_{j}+\alpha^{R}\left(p_{j m t}-b_{j m t}^{A}\left(p_{j m t}\right)\right)+\text { Firm }_{f(j)}^{d}+\text { Province }_{m}^{d}+\text { Time }_{t}^{d}+\xi_{j m t} .
\end{aligned}
$$

Some taste parameters are allowed to differ across residence locations. However, our sales data are not residence-location specific, so the identification of such taste differences depends on the variation of rural/urban population proportions across provinces and time. Intuitively, consider two identical provinces except that the percentage of rural residents is higher in province A than in province B. If the total market share of high-priced products is smaller in province $\mathrm{A}$ than in province $\mathrm{B}$, then such a data pattern indicates that rural residents are more sensitive to price than urban residents.

We estimate the demand parameters using the Generalized Method of Moments. The prices and market shares in the demand model are endogenous in the sense that they are correlated with $\xi_{j m t}$, the unobserved component of mean utility. We use the following instrumental variables to deal with this endogeneity issue. First, following the literature, we construct BLP instruments based on the characteristics of other products of the same firm, or products of competing firms, or "close" products. ${ }^{9}$ Second, since the differences between rural and urban tastes are identified by variations in the population proportions of consumer types, our additional instrumental variables are the population proportions and their interactions with the BLP instruments. The market size used in the demand estimation is $10 \%$ of the population in the corresponding province and time, and our results are robust to alternative market size measures.

\subsection{Supply Estimation}

The optimality conditions derived in Section 4.2 show that equation (7) holds for non-eligible products or eligible products with non-binding price ceilings, and inequality (8) holds for eligible products with binding price ceilings. Consequently, we can back out the marginal costs for some products (i.e., marginal costs are "point identified"), but there may be a set of marginal cost values that satisfy the optimality conditions for the other products ("set identified"). In this section, we estimate the marginal costs for a subset of products and the underlying marginal cost distribution for all products. In the counterfactual simulations in the next section, we use the estimated marginal costs for the "point identified" observations; for the observations whose corresponding marginal costs cannot be point identified, we draw marginal costs that are consistent with both the underlying distribution of marginal cost and the observed outcome as an equilibrium.

A comparison of our approach to the existing ones in the literature is in order. As explained in the introduction, different from Goldberg (1995) where a multi-product firm faces only one constraint, our

\footnotetext{
${ }^{9}$ Following Gandhi and Houde (2019), two products in the same market are "close" in a categorical characteristic if the two products are in the same category, and "close" in a numerical characteristic if the difference between the two products is less than the standard deviation of that characteristic in that market.
} 
firms face one constraint for each observation of eligible products, leading to many Lagrangian multiplier parameters to be estimated and no variation for identifying these parameters. We cannot follow the literature using moment inequalities for estimation (e.g., Pakes et al. (2015)) either. Note that inequality (8) includes a set of error terms (i.e., marginal cost shocks $\omega_{j^{\prime} m t}$ for all $j^{\prime} \in \mathcal{J}_{f m t}$ ), which do not enter the inequality in an additively separable fashion. Moreover, the optimality condition (8) does not generally imply inequalities in the form of $\underline{c}_{j m t} \leq m c_{j m t} \leq \bar{c}_{j m t}$, where $\underline{c}_{j m t}$ and $\bar{c}_{j m t}$ are constants. ${ }^{10}$ As a result, a moment assumption such as $E\left(\omega_{j m t}\right)=0$ does not imply moment inequality conditions.

We now turn to our approach. Note that for an observation $j m t$, as long as its firm has any product $j^{\prime}$ in this market $m t$ with a binding price ceiling so that we have inequality (8) for $j^{\prime} m t$, we cannot back out $m c_{j m t}$ even if the equation (7) holds for this $j m t$ itself. Therefore, we partition the observations by firm/market combinations: (A) observations of firms with no eligible products in the market: $\left\{j m t: \mathcal{J}_{f(j) m t}^{e}=\emptyset\right\}$; (B) observations such that some of the firm's products are eligible in the market but none of the corresponding price ceilings are binding: $\left\{j m t: \mathcal{J}_{f(j) m t}^{e} \neq \emptyset, p_{j^{\prime} m t}<\bar{p}_{j^{\prime} t}, \forall j^{\prime} \in \mathcal{J}_{f(j) m t}^{e}\right\} ;(\mathrm{C})$ observations such that at least one product of its firm in the market is both subsidized and has a binding pricing constraint: $\{j m t$ : $\exists j^{\prime} \in \mathcal{J}_{f(j) m t}^{e}$ s.t. $\left.p_{j^{\prime} m t}=\bar{p}_{j^{\prime} t}\right\}$.

For observations in both Samples (A) and (B), the equation (7) holds for all the products of the corresponding firm $f(j)$ in the market $m t$. Therefore, we can back out the marginal cost as

$$
m c_{j m t}=p_{j m t}+\left[\Delta_{f m t}^{-1} \boldsymbol{s}_{f m t}\right]_{j m t}, \forall j \in \mathcal{J}_{f m t},
$$

where $\boldsymbol{s}_{f m t}=\left(s_{j m t}\right)_{j \in \mathcal{J}_{f m t}}$ and $\Delta_{f m t}$ is a $\left|\mathcal{J}_{f m t}\right| \times\left|\mathcal{J}_{f m t}\right|$ matrix whose $\left(j, j^{\prime}\right)$ element is $\frac{\partial s_{j^{\prime} m t}}{\partial p_{j m t}}, \forall j, j^{\prime} \in \mathcal{J}_{f m t}$.

We estimate the distribution of marginal costs as follows. Under the timing assumption explained at the end of Section 4.2, the distribution of marginal cost shocks conditional on Sample (A) (i.e., observations that belong to firm/markets with no eligible products) equals the unconditional distribution: $F\left(\omega_{j m t} \mid j m t \in A\right)=$ $F\left(\omega_{j m t}\right)$. Therefore, we can estimate the distribution $F\left(\omega_{j m t}\right)$ using observations in Sample $(\mathrm{A})$. For these observations, we plug in the backed-out marginal costs from (13) into the marginal cost specification (9) and estimate the marginal cost parameters $\left(\hat{\gamma}, \hat{F i r m}_{f}^{s}\right.$, Province $\left._{m}^{s}, \operatorname{Time}_{t}^{s}\right)$ using the Generalized Methods of Moments. ${ }^{11}$ The estimated marginal cost shocks $\hat{\omega}_{j m t}$ for $j m t \in A$ are used to estimate the distribution $\hat{F}\left(\omega_{j m t}\right)$. Note that although we can back out the marginal cost for observations in Sample (B), we do not use these observations to estimate the distribution because they are selected. These observations are from firms that price all subsidized products strictly below the price ceilings, a decision made after observing the marginal cost shocks.

For observations in Sample (C), we draw the marginal costs that are consistent with both the estimated underlying distribution of marginal cost and the observed outcome as an equilibrium. To do so,

\footnotetext{
${ }^{10}$ Therefore, we cannot easily construct bounds for these marginal costs either.

${ }^{11}$ We estimate the firm fixed effects for the 17 largest firms separately and a group of all other fringe firms. These 17 firms account for $93.33 \%$ of the observations.
} 
we proceed with the following steps. For each firm/market $f m t$ with some observation(s) in Sample (C), we simulate draws of marginal cost shocks from the estimated distribution $\hat{F}\left(\omega_{j m t}\right)$. Denote such a draw as $\left(\omega_{j m t}^{r}\right)_{j \in \mathcal{J}_{f m t} \cap C}$ where $\omega_{j m t}^{r} \stackrel{i . i . d .}{\sim} \hat{F}(\cdot)$. We then compute the corresponding marginal costs as $\hat{\gamma} X_{j}+$ Firm $_{f}^{s}+$ Province $_{m}^{s}+$ Time $_{t}^{s}+\omega_{j m t}^{r}$ and keep the draws such that these marginal costs satisfy all optimality conditions of this firm/market. ${ }^{12}$ We repeat this process for all firm/markets in Sample (C).

To sum up, the procedure for estimating the supply model (and obtaining marginal cost draws for sample (C) in counterfactual simulations) is as follows:

Step (i). Estimate marginal costs for Samples (A) and (B) using first-order conditions and demand estimates, and denote the results by $\left(\boldsymbol{m} \boldsymbol{c}_{A}, \hat{\boldsymbol{m}} \boldsymbol{c}_{B}\right)$;

Step (ii). Estimate marginal cost coefficients and marginal cost shocks $\left(\hat{\boldsymbol{\omega}}_{A}\right)$ using Sample $(\mathrm{A})$ only;

Step (iii). Use $\hat{\boldsymbol{\omega}}_{A}$ to estimate the empirical distribution of marginal cost shocks $(\hat{F}(\omega))$;

Step (iv). Draw marginal cost shocks for Sample (C), as explained above. Denote the corresponding marginal cost draws by $\boldsymbol{m} \boldsymbol{c}_{C}^{r}, r=1, \ldots, R$, where $R$ is the number of simulation draws.

Step (v). Use ( $\left.\boldsymbol{m} \boldsymbol{c}_{A}, \boldsymbol{m} \boldsymbol{c}_{B}, \boldsymbol{m} \boldsymbol{c}_{C}^{r}\right)$ to conduct counterfactual simulations.

\subsection{Estimation Results}

Table 2 reports the demand estimation results. We allow the coefficients on price and the constant term to be different between rural and urban consumers. The differences have the expected signs and are significant. Compared to urban consumers, ceteris paribus, rural consumers are more sensitive to price (perhaps because of their lower average income). They are also more likely to purchase a cell phone (probably because fewer of them already own a cell phone). We allow for the random coefficient on price, but its estimated dispersion is small and statistically insignificant. ${ }^{13}$ The estimated coefficient for the eligibility dummy is negative, probably because the HAGC products are mostly low-end products and the dummy variable captures some unobservable features of these products. All the coefficients on favorable product characteristics are positive and significant as expected. ${ }^{14}$ For example, to an average rural consumer, upgrading from a feature phone to a smartphone is equivalent to a price decrease by about $96 \mathrm{CNY}$.

Table 3 reports the marginal cost estimation results using the same instrumental variables as the demand estimation. We assume that firms maximize their profits from rural consumers rather than from all consumers for two reasons. First, according to industry analysis reports, the major firms focused on expanding their businesses for their low-end products in rural areas during the sample period, partially in response to the HAGC program. Second, when we assume that a firm's objective function is a weighted average of profits as $w \pi_{\text {rural }}+(1-w) \pi_{\text {urban }}$, where $\pi_{\text {rural }}\left(\right.$ or $\left.\pi_{\text {urban }}\right)$ is the profit from rural (or urban) consumers, and

\footnotetext{
${ }^{12}$ In practice, if we draw all marginal cost shocks for a market, it is nearly impossible that they will satisfy the equations in the optimality conditions. So, we draw shocks for the observations with binding constraints, compute the other shocks using the optimality equations, and then take all drawn or computed shocks to verify the optimality inequalities.

${ }^{13}$ Therefore, we assume the standard deviation of the random coefficient to be zero in the remainder of the paper.

${ }^{14}$ The three continuous variables of characteristics, namely storage, rear camera resolution, and handset size, are normalized to have an absolute value between zero and one so that the magnitudes of their coefficients are comparable to those of dummy variables.
} 
estimate both marginal cost coefficients and $w$ as an additional coefficient, we indeed obtain an estimate of $\hat{w}=0.98 .^{15}$

Table 2: Estimation Results on Demand

\begin{tabular}{lcc}
\hline Variable & Est. & S.E. \\
\hline Constant: Rural & $-6.03^{* * *}$ & $(0.09)$ \\
Constant: Urban - Rural & $-2.05^{* * *}$ & $(0.14)$ \\
Retail Price: Rural & $-5.72^{* * *}$ & $(1.08)$ \\
Retail Price: Urban - Rural & $4.91^{* * *}$ & $(0.22)$ \\
Price random coefficient std. & 0.001 & $(0.72)$ \\
Being eligible for subsidy & $-0.03^{* * *}$ & $(0.01)$ \\
Smartphone (v.s. feature phone) & $0.55^{* * *}$ & $(0.02)$ \\
Include camera & $0.84^{* * *}$ & $(0.05)$ \\
Include touch screen & $0.27^{* * *}$ & $(0.01)$ \\
Support 3G network & $0.23^{* * *}$ & $(0.01)$ \\
Dual SIM card & $0.04^{* * *}$ & $(0.01)$ \\
Design: flip & $0.47^{* * *}$ & $(0.02)$ \\
Design: slider & $0.43^{* * *}$ & $(0.01)$ \\
Storage memory (normalized) & $1.29^{* * *}$ & $(0.04)$ \\
Camera resolution (normalized) & $2.83^{* * *}$ & $(0.11)$ \\
Handset size (normalized) & $5.95^{* * *}$ & $(0.17)$ \\
Nested Logit coefficient & $0.26^{* * *}$ & $(0.01)$ \\
Province, time, and firm dummies & \multicolumn{2}{c}{ Yes } \\
\hline
\end{tabular}

$* * * \mathrm{p}<0.01 .,{ }^{* *} \mathrm{p}<0.05,{ }^{*} \mathrm{p}<0.10$.

Table 3: Estimation Results on Marginal Cost

\begin{tabular}{lcc}
\hline Variable & Est. & S.E. \\
\hline Constant & $-1.03^{* * *}$ & $(0.028)$ \\
Smartphone (v.s. feature phone) & $0.32^{* * *}$ & $(0.005)$ \\
Include camera & $0.55^{* * *}$ & $(0.003)$ \\
Include touch screen & $0.005^{*}$ & $(0.003)$ \\
Support 3G network & $0.04^{* * *}$ & $(0.003)$ \\
Dual SIM card & $0.04^{* * *}$ & $(0.003)$ \\
Design: flip & $0.32^{* * *}$ & $(0.004)$ \\
Design: slider & $0.33^{* * *}$ & $(0.004)$ \\
Storage memory (normalized) & $0.18^{* * *}$ & $(0.014)$ \\
Camera resolution (normalized) & $2.86^{* * *}$ & $(0.013)$ \\
Handset size (normalized) & $3.33^{* * *}(0.062)$ \\
Province, time, and firm dummies & \multicolumn{2}{c}{ Yes } \\
\hline
\end{tabular}

*** $\mathrm{p}<0.01 .,{ }^{* *} \mathrm{p}<0.05,{ }^{*} \mathrm{p}<0.10$.

The estimation results show that marginal cost, as expected, is positively associated with all product characteristics and significantly so with most ones. The characteristics that consumers care about most, namely rear camera resolution and handset size, also have the largest marginal cost coefficients.

\footnotetext{
${ }^{15}$ The weight parameter $w$ is identified by rural population proportion variations across markets.
} 


\section{Counterfactual Simulations}

We conduct counterfactual simulations to quantify the welfare effect of the subsidy program and highlight the role of competition for eligibility (which determines the price ceilings and the eligible product set).

In each simulation, we draw marginal cost shocks as described by Step (iv) in Section 5.2, solve for the new pricing equilibrium for each market, compute the corresponding total government subsidy payments, consumer surplus, and producer surplus, and report averages across simulation draws. We use the bootstrap method for standard errors. Specifically, we repeat the above process for different draws of the model parameters from the estimated distribution.

We conduct three counterfactual simulations where the subsidy rate for eligible purchases is the same as in the data, i.e., $13 \%$ of the retail price up to a maximum subsidy of $130 \mathrm{CNY}$. Table 4 summarizes the counterfactual designs. In the first counterfactual simulation (CF1), we simulate what would have happened if there were no subsidy at all. The comparison of such simulation results to outcomes according to the data gives us the overall effect of the HAGC subsidy program, i.e., the subsidy combined with firms' competition for subsidy eligibility, which restricts the subsidy to a set of eligible products and leads to a price ceiling for each eligible product. In the second counterfactual simulation (CF2), we simulate what would have happened if the same set of products as in the data were eligible for the subsidy but there were no pricing ceilings. Comparing the outcomes from $\mathrm{CF} 2$ and those according to the data allows us to quantify the effect of price ceilings. In the third counterfactual simulation (CF3), we simulate the effect of an alternative program where there is no competition for eligibility at all, i.e., all products were eligible for the subsidy and there were no price ceilings. The comparison of its results to those of CF2 informs us about the effect of enlarging the set of eligible products (to all products).

Table 4: Counterfactual Simulations

\begin{tabular}{cccc}
\hline Counterfactual & $\begin{array}{c}\text { Eligible } \\
\text { product set }\end{array}$ & $\begin{array}{c}\text { Price } \\
\text { ceilings }\end{array}$ & $\begin{array}{c}\text { The comparison v.s. CF1 } \\
\text { gives the effect of ... }\end{array}$ \\
\hline Data & Actual & Actual & Subsidy + eligible set + ceiling \\
CF1 & None & None & \\
CF2 & Actual & None & Subsidy + eligible set \\
CF3 & All & None & Subsidy \\
\hline
\end{tabular}

Table 5 reports the price effects. We divide the simulated equilibrium price of each observation by the price of the same observation in the case with no subsidy (i.e., CF1) to compute the percentage change. We then take the average across marginal cost shock draws. We report the average across all observations within three different groups (i.e., observations for ineligible products, eligible products without binding constraints, and eligible products with binding constraints) corresponding to Columns (1) - (3). The first row gives us the overall effect of the HAGC subsidy program. We can see that this subsidy program with firms' competition for subsidy eligibility leads to a reduction in price for some products while an increase 
for other products. Compared to a scenario without the subsidy program, the prices of the eligible products with binding price ceilings in the data are $10.05 \%$ lower on average (Column (3)) while other products' prices increase on average (Columns (1) and (2)). Intuitively, when consumers are eligible for subsidies, demand shifts to the right, and, consequently, firms are likely to raise prices. The opposite effect for some products (i.e., reduction in prices) that we find indicates that the competition for eligibility provides an incentive for firms to submit "competitive" price ceilings and thus dampens the price increases arising from the subsidy.

We can also see this dampening effect by comparing the first row to the second row, where we remove the price ceilings and find higher prices for all products. For example, without price ceilings, the price change for products in Column (3) moves from $-10.05 \%$ to $3.45 \%$. Similarly, the price increases in Columns (1) and (2) are smaller in the first row than in the second row. This is because prices are strategic complements and thus the price ceilings (as a result of the competition for eligibility) not only lower the prices of the eligible products (Columns (2) and (3)) but also reduce the prices of ineligible products (Column (1)). For the same intuition, when the subsidy program applies to all products without price ceilings, the prices increase even more (the last row). To sum up, competition for eligibility mitigates price increases due to the subsidy and even leads to a reduction in prices for some products (compared to the prices without the subsidy program).

Table 5: Price Changes (\%) Compared to the Case without Subsidy

\begin{tabular}{|c|c|c|c|c|}
\hline The effect of ... & & (1) & $(2)$ & $(3)$ \\
\hline Subsidy + eligible set + ceiling & (Data - CF1) & $\begin{array}{c}0.06 \\
(0.21)\end{array}$ & $\begin{array}{c}5.03 \\
(3.26)\end{array}$ & $\begin{array}{c}-10.05 \\
(4.29)\end{array}$ \\
\hline Subsidy + eligible set & (CF2 - CF1) & $\begin{array}{c}0.07 \\
(0.22)\end{array}$ & $\begin{array}{c}5.06 \\
(3.28)\end{array}$ & $\begin{array}{c}3.45 \\
(2.02)\end{array}$ \\
\hline Subsidy & (CF3 - CF1) & $\begin{array}{c}2.53 \\
(3.11)\end{array}$ & $\begin{array}{c}5.22 \\
(3.54)\end{array}$ & $\begin{array}{c}3.55 \\
(2.06)\end{array}$ \\
\hline
\end{tabular}

Each column is the average across the following observations based on their status in the data, i.e., under the actual HAGC subsidy program. Standard errors are reported in parentheses.

(1): the observations for ineligible products;

(2): the observations for eligible products with no biding constraints;

(3): the observations for eligible products with biding constraints.

We turn to the welfare effects in Table 6 . In this table, Column (1) reports the total government subsidy payment amount. Columns (2)-(6) present consumer and producer surplus changes and their ratios to the total subsidy amount in Column (1). Column (7) on $\Delta C S /(\Delta C S+\Delta P S)$ shows how the welfare change is split between consumer surplus and producer surplus.

From the first row, we can see that the HAGC subsidy program increases overall consumer surplus by 3.07 billion CNY (Column (4)). Specifically, subsidy-eligible consumers are 3.70 billion CNY better off (Column (5)), while subsidy-ineligible consumers are 0.62 billion CNY worse off (Column (6)). These results are consistent with the price change pattern shown in Table 5. Even though firms' competition for subsidy eligibility mitigates the price increases arising from the subsidy, the prices of many products increase due 
to the subsidy program, leading to a decrease in the consumer surplus of ineligible consumers. In the end, both overall consumer surplus and producer surplus increase, with $53 \%$ of the total surplus increase going to consumers (Column (7)). Moreover, the sum of consumer and producer surplus increases outweighs the subsidy amount: the total surplus increase is $129 \%$ of the total government subsidy payments (Column (2)). Therefore, under the assumption that the program leads to a tax increase and the welfare cost of raising 1 CNY tax revenue is lower than 0.29 CNY, there is a total welfare gain in the economy under the HAGC subsidy program.

In contrast, when price ceilings are removed (middle row), consumers, both subsidy-eligible and ineligible ones, are worse off (Columns (4) to (6)) while producers are better off (Column (2)), compared to when price ceilings are present (first row). As a result, the ratio $\Delta C S /(\Delta C S+\Delta P S)$ reduces to $48 \%$, indicating that the price ceiling component of the competition for eligibility mitigates the pass-through of subsidy from consumers to firms.

The last row shows that a hypothetical subsidy to all products without the competition for eligibility would result in larger increases in all welfare measures (except for surplus for ineligible consumers due to the greater price increases). However, total government subsidy payments would be 27.41 billion CNY, more than six times the payments under the actual HAGC subsidy program (4.54 billion CNY). This result indicates that specifying a set of eligible products may be necessary for making the subsidy financially feasible. In Appendix B, we investigate an alternative policy, which is similar to CF3 except that the subsidy rate is lower so that the total government subsidy payments remain the same. We find that the targeted consumers are worse off under this alternative policy.

Table 6: Welfare Changes Compared to the Case without Subsidy

\begin{tabular}{lccccccc}
\hline \multicolumn{1}{c}{ The effect of ... } & $(1)$ & $(2)$ & $(3)$ & $(4)$ & $(5)$ & $(6)$ & $(7)$ \\
& $\begin{array}{c}\text { Total } \\
\text { Subsidy }\end{array}$ & $\begin{array}{c}\Delta P S \\
+\Delta C S\end{array}$ & $\Delta P S$ & $\Delta C S$ & $\Delta C S^{A}$ & $\Delta C S^{N A}$ & $(4) /(2)$ \\
\hline Subsidy + eligible set + ceiling & 4.54 & 5.84 & 2.77 & 3.07 & 3.70 & -0.62 & $53 \%$ \\
(Data - CF1) & $(0.13)$ & $(0.24)$ & $(0.07)$ & $(0.27)$ & $(0.19)$ & $(0.08)$ & \\
& & $129 \%$ & $61 \%$ & $68 \%$ & $81 \%$ & $-14 \%$ & \\
Subsidy + eligible set & 4.53 & $(1.76 \%)$ & $(2.47 \%)$ & $(4.10 \%)$ & $(2.30 \%)$ & $(2.05 \%)$ & \\
(CF2 - CF1) & $(0.13)$ & $(0.25)$ & $(0.09)$ & $(0.32)$ & $(0.22)$ & $(0.10)$ & \\
& & $126 \%$ & $66 \%$ & $61 \%$ & $77 \%$ & $-16 \%$ & \\
Subsidy & & $(2.16 \%)$ & $(3.26 \%)$ & $(5.33 \%)$ & $(3.03 \%)$ & $(2.48 \%)$ & \\
(CF3 - CF1) & 27.41 & 36.40 & 10.26 & 26.14 & 28.34 & -2.19 & $72 \%$ \\
& $(1.54)$ & $(1.94)$ & $(0.58)$ & $(1.97)$ & $(1.70)$ & $(0.31)$ & \\
& & $133 \%$ & $37 \%$ & $95 \%$ & $103 \%$ & $-8 \%$ & \\
\hline
\end{tabular}

The unit of absolute numbers in white background color is billion CNY. The percentages in gray background color are the ratio of the welfare change in each column to the corresponding government subsidy payment amount in Column (1). In parentheses are the standard errors, in either billion CNY or percentages. "A" in Column (5) stands for eligible consumers with agricultural Hukou, and "NA" in Column (6) for ineligible consumers with non-agricultural Hukou. 
Overall, these results show that the competition for eligibility provides incentives for firms to submit low price ceilings in order to be qualified for the subsidy. Such incentives lead to lower prices for all products, including non-eligible products, because of the strategic complementarity of prices and thus mitigate the price increases arising from the subsidy (to the extent that the prices of some products even dropped). In the end, this program design (i.e., competition for eligibility) improves consumer surplus in levels and the pass-through rate while limiting government spending on subsidies.

\section{Conclusion}

In this paper, we quantify the welfare effect of a consumer subsidy program and the role of firms' competition for subsidy eligibility. We develop an estimation procedure that accommodates multiple consumer types and binding pricing constraints. Through a set of counterfactual simulations, we find that the eligible product set and associated price ceilings, two critical components of the competition for eligibility, mitigated price increases under subsidy and benefited consumers and society while limiting the required government subsidy payments.

These results suggest that a consumer subsidy can improve total welfare in an imperfectly competitive market, and a policy can be designed to mitigate upward pricing pressure due to a subsidy, generate additional total welfare gains, and allow consumers to take a larger share of the subsidy program's benefits.

\section{References}

Berry, Steven, James Levinsohn, and Ariel Pakes (1995), "Automobile prices in market equilibrium." Econometrica: Journal of the Econometric Society, 841-890.

Cabral, Marika, Michael Geruso, and Neale Mahoney (2018), "Do larger health insurance subsidies benefit patients or producers? Evidence from Medicare Advantage." American Economic Review, 108, 2048-87.

Chen, Cheng, Shin-Yi Chou, and Robert J Thornton (2015), "The effect of household technology on weight and health outcomes among Chinese adults: Evidence from China's 'Home Appliances Going to the Countryside' policy." Journal of Human Capital, 9, 364-401.

Davis, David E (2014), "Buyer alliances as countervailing power in WIC infant-formula auctions." Review of Industrial Organization, 45, 121-138.

Decarolis, Francesco, Maria Polyakova, and Stephen P Ryan (2020), "Subsidy design in privately provided social insurance: Lessons from Medicare Part D." Journal of Political Economy, 128, 1712-1752.

Fan, Ying and Chenyu Yang (2020), "Competition, product proliferation, and welfare: A study of the US smartphone market." American Economic Journal: Microeconomics, 12, 99-134.

Gandhi, Amit and Jean-François Houde (2019), "Measuring substitution patterns in differentiated products industries." NBER Working Paper w26375. 
Goldberg, Pinelopi Koujianou (1995), "Product differentiation and oligopoly in international markets: The case of the US automobile industry." Econometrica: Journal of the Econometric Society, 891-951.

Oliveira, Victor, Elizabeth Frazão, David Smallwood, et al. (2010), "Rising infant formula costs to the WIC program: recent trends in rebates and wholesale prices." Economic Research Report-Economic Research Service, USDA.

Pakes, Ariel, Jack Porter, Kate Ho, and Joy Ishii (2015), "Moment inequalities and their application." Econometrica, 83, 315-334.

Pless, Jacquelyn and Arthur A van Benthem (2019), "Pass-through as a test for market power: An application to solar subsidies." American Economic Journal: Applied Economics, 11, 367-401.

Polyakova, Maria and Stephen P Ryan (2019), "Subsidy targeting with market power." NBER Working Paper w2636\%.

Sallee, James M (2011), "The surprising incidence of tax credits for the Toyota Prius." American Economic Journal: Economic Policy, 3, 189-219.

Sinkinson, Michael (2020), "Pricing and entry incentives with exclusive contracts." Unpublished manuscript.

Tewari, Ishani and Yabin Wang (2020), "Durable ownership, time allocation and female labor force participation: Evidence from China's 'Home Appliances to the Countryside' rebate." Economic Development and Cultural Change, forthcoming.

Wang, Fei-Ling (2014), The Hukou (household registration) system. Oxford University Press.

Wang, Peichun (2020), "Product portfolio choices with product life cycles." Unpublished manuscript.

Weyl, E Glen and Michal Fabinger (2013), "Pass-through as an economic tool: Principles of incidence under imperfect competition." Journal of Political Economy, 121, 528-583.

Zhu, Ting, Hongju Liu, and Pradeep K Chintagunta (2015), "Wireless carriers' exclusive handset arrangements: An empirical look at the iPhone." Customer Needs and Solutions, 2, 177-190.

\section{A Appendix: Sample Construction}

We construct our sample for analysis as follows. We first drop observations from Beijing, Shanghai, Tibet, and online sales. Beijing and Shanghai have only a small share of consumers eligible to claim the HAGC subsidy and thus are not very relevant to our analysis of the subsidy program. Moreover, consumers in such super metropolises may have different preferences on cell phones. At the other extreme, Tibet has a very small population and very low cell phone sales, leading to imprecise measures of the average prices reported by GfK. Finally, we drop online sales because our data source reports online sales only at the national level without providing a breakdown at the province level. Overall, the online sales account for $8.75 \%$ of the total sales units in the full sample.

We aggregate the data from the original monthly level to the quarterly level by summing up the sales 
units and taking the sales-weighted average for prices. ${ }^{16}$ We do so because quarterly sales are measured more precisely than monthly ones. We then drop an observation (a product/province/quarter combination) if its number of sales units is no larger than 500 or accounts for less than $0.1 \%$ of the total sales units in that province and quarter. We also drop a product if its price is always above 2,000 CNY in the sample. The HAGC-eligible products are mostly low-end products priced below 1,000 CNY. Thus, the high-end products and their targeted consumers have little influence on the welfare analysis of the subsidy program for low-end products. Finally, we drop an observation if the product is released or discontinued in the quarter because the sales in such cases are highly subject to (unobserved) product inventory and do not necessarily reflect underlying consumer preferences. All these dropped products are part of the outside option.

\section{B Appendix: Alternative Subsidy Policy Designs}

This appendix presents the welfare results for an alternative subsidy policy that is similar to that in CF3. We have seen in Section 6 that the policy in CF3, i.e., a universal subsidy at the actual 13\% rate (of the retail price up to a maximum subsidy of $130 \mathrm{CNY}$ ), would result in subsidy payments that might not be financially feasible. In this appendix, we consider a universal subsidy at a $2 \%$ rate instead, which turns out to imply an average total subsidy payment amount (4.64 billion CNY) close to that under the actual policy (4.54 billion CNY). ${ }^{17}$

Table B.1 adds its last rows to Table 6 to show the results of the counterfactual simulations mentioned above. Table B.1 also adds its Columns (7) to (10) to show the welfare changes for different subgroups of consumers by both Hukou (and thus subsidy eligibility) and residence location. The results indicate that the hypothetical $2 \%$ universal subsidy would bring higher overall consumer surplus gains than the actual policy.

However, as we discuss in Section 2.3 and as the name "Home Appliances Going to the Countryside" implicates, the HAGC subsidy program aimed to help consumers from rural areas with relatively low income despite that the subsidy eligibility was based on Hukou type as a proxy of rural residence. The further breakdown of consumer surplus reveals that the consumers with agricultural Hukou in the rural area, the real target of the HAGC subsidy program, would have larger welfare gain under the actual program (1.46 billion CNY) than under the hypothetical $2 \%$ universal one ( 0.81 billion CNY). These results are intuitive since the government selected the products that best met the needs of targeted consumers and was able to offer the $13 \%$ (much higher than $2 \%$ ) subsidy rate by restricting to a smaller range of eligible products.

Therefore, which policy design is better depends on the government's objective function. For example, suppose the government puts a relatively large weight on the welfare of consumers with agricultural Hukou in the rural area. In that case, it should choose the actual policy design with selected eligible products

\footnotetext{
${ }^{16}$ The three months in a quarter may not belong to the same round of HAGC subsidy. In such cases, we aggregate the two months belonging to the same round into one observation and keep the other single month as a separate observation. We make corresponding adjustments when calculating market shares. For simplicity, we still use "quarter" to refer to such observations.

${ }^{17}$ We find out the rate to be about $2 \%$ by trying different subsidy rates and comparing the implied subsidy payment amount to that under the actual policy. Here we suppose only consumers with agricultural Hukou are eligible for the subsidy, the same as in the actual policy.
} 
(together with a higher subsidy rate and price ceilings) over the hypothetical $2 \%$ universal one according to our simulation results. ${ }^{18}$

\footnotetext{
${ }^{18}$ There are some other operational reasons (that are not in the scope of our economic analysis) for not expanding the subsidy to all products. For example, the government did quality examinations on each participating cell phone model to ensure it would meet the needs of eligible consumers, which would be less practicable for all the thousands of models. Limiting the set of eligible products also made it easier for the government to prevent abuse and fraud in the rebate redemption.
} 


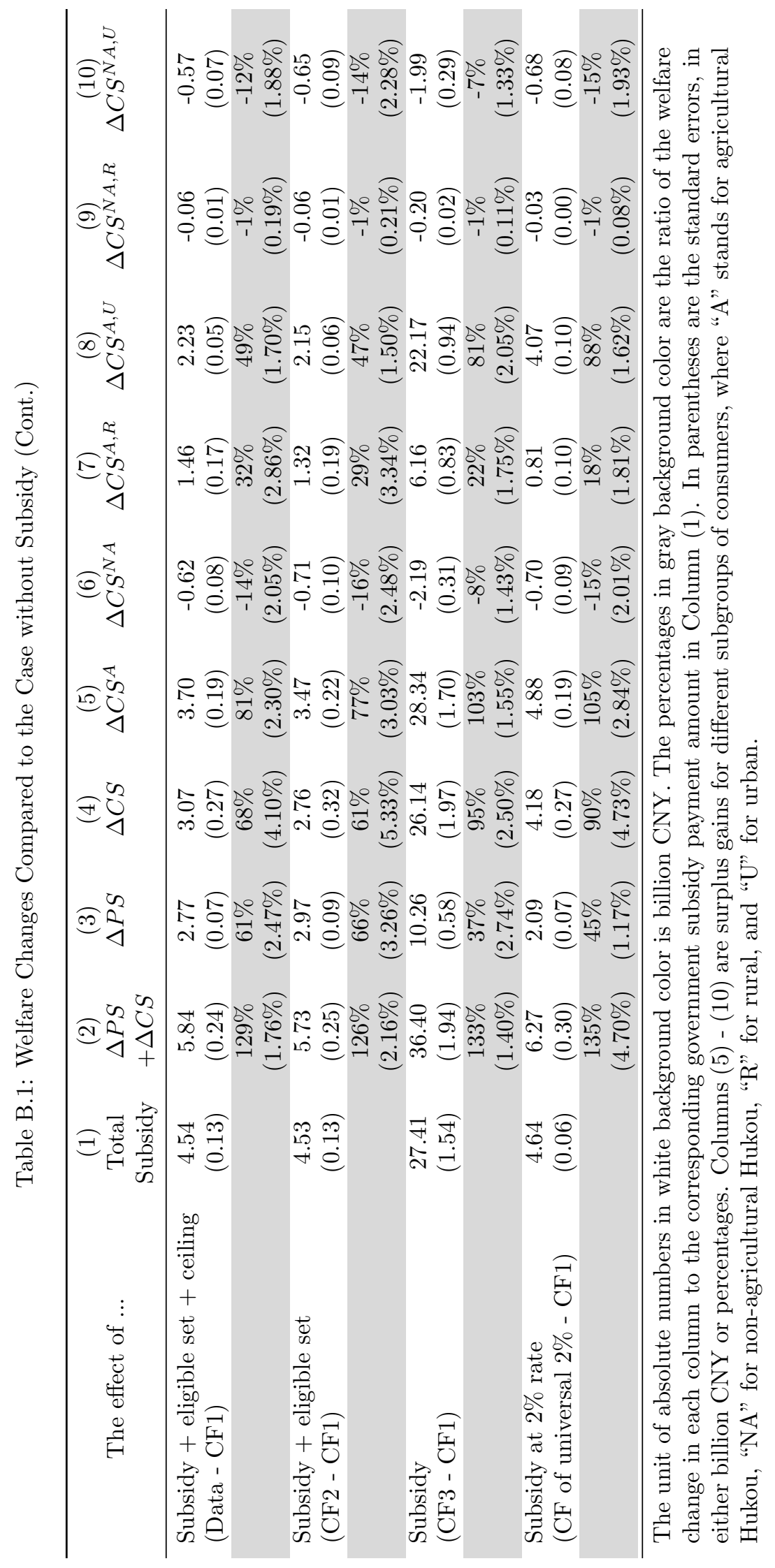

